\title{
Psicologia Sócio-histórica como fundamento para a compreensão das significações da atividade docente
}

\author{
Socio-historical Psychology as the basis \\ for understanding teaching practice
}

\author{
Wanda Maria Junqueira de AGUIAR \\ Virgínia Campos MACHADO²
}

\begin{abstract}
Resumo
Este artigo apresenta e discute a importância de produzir conhecimento a respeito dos aspectos subjetivos que constituem a atividade docente, buscando compreendê-la para além de sua aparência, em suas contradições e mediações. Propõe-se aqui a discussão dos pressupostos teóricos da Psicologia Sócio-histórica, a qual, por sua vez, fundamenta-se no Materialismo Histórico e Dialético. Estes dois últimos orientam as pesquisas realizadas pelo grupo "Atividade docente e subjetividade", o qual tem contribuído para a produção de conhecimento crítico na área da educação. Para tanto, inicia-se discutindo categorias como: Mediação, Historicidade, Atividade, Sentidos, Significados e Subjetividade. Em seguida, passa-se aos conceitos "real da atividade" e "atividade real" e os procedimentos de Autoconfrontação Simples e Cruzada propostos por Yves Clot. Enfatiza-se a importância do referencial teórico em todas as etapas da pesquisa, visto ser um critério de cientificidade do conhecimento produzido, e a necessária articulação entre todos esses momentos.
\end{abstract}

Palavras-chave: Atividade docente; Psicologia sócio-histórica; Sentidos; Significado.

\begin{abstract}
This article seeks to address the importance of producing knowledge about the subjective aspects of teaching practice in order to understand it beyond its theoretical definitions, i.e., to acknowledge its contradictions and mediations. This study presents a discussion of the theoretical assumptions of Socio-historical Psychology, which is rooted in the dialectical and historical materialism, which, in turn, are the basis for the studies conducted by the research group "Teaching practice and subjectivity". These studies have made major contributions to the critical knowledge in education. The present article initially discusses categories such as Mediation, Historicity, Activity, Senses, Meanings, and Subjectivity. Subsequently, the concepts of "real practice" and "real life practice" are introduced, followed by the simple and crossed self-confrontation techniques proposed by Yves Clot. It is essential to highlight the importance of the theoretical framework to support the entire process of the research since it is a scientificity criterion of the produced knowledge and the required coordination between all research steps.
\end{abstract}

Keywords: Teaching activity; Sociohistorical psychology; Senses; Meaning.

\footnotetext{
$\nabla \nabla \nabla$

1 Pontifícia Universidade Católica de São Paulo, Faculdade de Educação, Programa de Estudos Pós-Graduados em Educação: Psicologia da Educação. R. Monte Alegre, 984, Perdizes, 05014-901, São Paulo, SP, Brasil. Correspondência para/Correspondence to: W.M.J. AGUIAR. E-mail: <iajunqueira@uol.com.br>.

2 Universidade Federal da Bahia, Faculdade de Nutrição, Departamento de Ciência da Nutrição. Salvador, BA, Brasil.
} 
Este artigo tem como objetivo apresentar e discutir o referencial teórico-metodológico que fundamenta as pesquisas realizadas pelo grupo "Atividade docente e subjetividade". O grupo é parte integrante do Programa de Estudos Pós-Graduados em Educação: Psicologia da Educação da Pontifícia Universidade Católica de São Paulo. Esse esforço é importante, pois, por meio da explicitação dos fundamentos que orientam esta pesquisa é possível evidenciar a necessidade da coerência em relação à concepção do objeto de estudo deste trabalho e o modo como os autores lidam com ele ao longo do processo de produção de conhecimento.

Este trabalho vai ao encontro das ideias de Bourguignon (2006), que afirma que a produção de conhecimentos exige rigor teórico-metodológico e vinculação orgânica com demandas concretas problematizadas pelo pesquisador a partir de sua inserção na realidade social. Destaca-se, assim, o objeto de estudo como algo construído numa relação sempre mediada pela realidade e pelo referencial teórico o qual, sendo norteador da pesquisa, oferece as lentes por meio das quais o pesquisador enxerga o mundo e o fenômeno que investiga.

Portanto, considera-se que a produção do conhecimento se dá em contextos socialmente determinados e que a construção do objeto, bem como das interpretações feitas na tentativa de explicá-lo e de contribuir para sua transformação, fazem parte de um contínuo processo de construções teóricas as quais permitem novas e sucessivas aproximações em relação ao real. Retomando os escritos de Lefebvre (1979), Bourguignon (2006) descreve como características gerais do conhecimento: ser prático, social e histórico. Para a autora,

Essas reflexões levam a pensar a produção de conhecimento através da pesquisa como uma das modalidades da práxis, em que a relação da unidade teoria/prática pode efetivamente ser trabalhada, a partir da perspectiva filosófica e visão de mundo que orienta o pesquisador e profissional em sua visão de pesquisa (p.43).

Essas características gerais do conhecimento também podem ser discutidas com base em Lowy

262 (1987). Em Aventuras de Karl Marx contra o Barão de Munchhausen (Lowy, 1987), o autor apresenta o conceito de "Horizonte Intelectual" e discute o papel da ideologia na constituição de um saber científico, afirmando que ela circunscreve seus limites. Ele também apresenta a metáfora do mirante, transcrita abaixo, para discutir a questão da objetividade das interpretações sobre a realidade:

$$
\begin{aligned}
& \text { O mirante não faz senão definir uma possibi- } \\
& \text { lidade objetiva de visibilidade: a visão efetiva } \\
& \text { e a pintura de uma paisagem não depende } \\
& \text { mais dele. Mas trata-se de uma autonomia } \\
& \text { relativa e não de uma independência total } \\
& \text { (como pretende o positivismo) na medida } \\
& \text { em que o papel do horizonte de visibilidade } \\
& \text { é decisivo para a própria constituição do } \\
& \text { campo cognitivo (p.207). }
\end{aligned}
$$

Lowy (1987) esclarece, portanto, que as consciências possíveis numa sociedade de classes não se situam no mesmo plano, sendo que um único fato poderá ser interpretado de formas diferentes, a partir de distintas compreensões da realidade. Já Mészáros (2004a) alerta para o fato de que a ideologia penetra em todos os espaços e "é constituída objetivamente como uma consciência prática inevitável numa sociedade de classes" (p.65). Para ele, ninguém nem nenhuma teoria pode eleger-se como sendo puramente "consensual, objetiva, científica", negando sua presença.

É nesse sentido que defende-se a reflexão crítica como instrumento e resultado no processo de construção do conhecimento. Em outros termos:

A reflexão sobre o real torna-se o momento em que o homem descobre as contradições existentes no real. Pela reflexão, a natureza dialética do real encontra, na consciência da contradição, sua expressão subjetiva, e também a possibilidade de uma interferência no real (Cury, 1985, p.32).

De acordo com Cury (1985), as contradições estão presentes no movimento dialético das múltiplas determinações que mutuamente constituem a realidade. A contradição "é o momento conceitual explicativo mais amplo, uma vez que reflete o movimento mais originário do real" (1985, p.27), permitindo ao analista interpretá-lo como síntese contraditória. 
O grupo de pesquisa "Atividade docente e subjetividade" tem se dedicado ao estudo dos aspectos subjetivos que constituem a atividade docente, tendo como base os pressupostos da Psicologia Sócio-histórica. Esta, por sua vez, tem como fundamento o Materialismo Histórico e Dialético, e busca produzir um conhecimento que contribua para permitir a ruptura do cotidiano alienado; pretende, ao captar o real em sua complexidade e apreender suas particularidades, superar os limites da espontaneidade, da fragmentação e da casualidade (Oliveira, 2005). Desse modo, procura afastar-se de uma abordagem da realidade que fique na aparência, na descrição dos fatos, não alcançando a compreensão do seu processo de constituição.

Para apreender os aspectos subjetivos que constituem a atividade docente, as pesquisas desenvolvidas pelo referido grupo problematizam, junto aos professores, a concepção de docência, de aluno, de processo de ensino-aprendizagem, assim como aspectos relativos à gestão escolar e ao real da atividade que tem lugar na sala de aula. Ao produzir estudos sobre a atividade docente, os quais entendam essa atividade "estendida aos movimentos da subjetividade" (Clot, 2006), é possível se aproximar de aspectos que não se revelam na aparência do fenômeno, mas são fundamentais quando se busca compreender a docência, bem como a possibilidade de transformação da sua qualidade.

Ao se estudar as significações da atividade docente para o professor, procura-se realizar um movimento analítico o qual deve incluir a apreensão dos elementos que, ao serem negados e superados, evidenciam as transformações, o surgimento do novo, o vir a ser da atividade. Para que esse processo se realize, os esforços se concentram na apreensão da gênese dos fenômenos, e o uso de categorias é fundamental.

Desse modo, o presente artigo tem como objetivo discutir o referencial teórico-metodológico da Psicologia Sócio-histórica, e algumas categorias do Materialismo Histórico e Dialético, da maneira como vêm sendo apreendido e utilizado nas pesquisas desenvolvidas pelo grupo "Atividade docente e Subjetividade". Acredita-se que esse esforço se justifica na medida em que esses fundamentos teórico-metodológicos se mostram capazes de contribuir para a apreensão do processo de constituição social da subjetividade humana.

\section{O referencial teórico-metodológico}

Como afirmado anteriormente, o referencial teórico-metodológico adotado pelo grupo de pesquisa baseia-se, fundamentalmente, na Psicologia Sócio-histórica, que tem por base o Materialismo Histórico e Dialético. Além disso, também incorpora contribuições de autores contemporâneos, como Clot $(2006,2010)$ e seu grupo de pesquisadores do Conservatoire National dês Arts et Métiers, que assumem, deliberadamente, filiação ao pensamento Vygotskiano.

No processo de produção de conhecimento sobre o real, as categorias balizam a reprodução do concreto por meio do pensamento. Elas possuem a universalidade como um de seus principais aspectos (Bernardes, 2011). São, nesse sentido, construtos abstratos os quais orientam o pesquisador no processo de construção de conhecimento sobre o real. Os conceitos, por sua vez, definem certa particularidade do objeto, mas são carentes de elementos para o entendimento da universalidade (ou totalidade) em que são compostos, levando a não possibilidade de apreenderem e revelarem o movimento contraditório do real.

As categorias permitem a apreensão da materialidade do real, de sua essência, que, por ser dialética, é também movimento, processo. Como afirma Aguiar, as categorias "... carregam o movimento do fenômeno estudado, sua materialidade, suas contradições e sua historicidade" (Aguiar, 2001, p.95). Elas são orientadoras da forma como se apreende o real (sendo que não existe nada imediato) e, portanto, sua utilização garantirá a apreensão das contradições, do movimento, enfim, do fenômeno concreto. E é na compreensão dessas relações que repousa a relevância do processo de produção do conhecimento.

A partir do entendimento de que o real é contraditório e de que nada é fixo e imutável, entende-se que o pensamento também deve se 
colocar em movimento e ser pensamento deste movimento, ser um pensamento consciente da contradição (Lefebvre, 1979). Em última instância, acredita-se que ao se lançar mão do pensamento categorial, criam-se possibilidades de desvelar a realidade da docência, incluindo-se aí as significações da atividade que são constituídas pelos professores.

As investigações do grupo de pesquisa aqui mencionado são orientadas pela ideia desenvolvida por Cury de que "os fatos só nos interessam na expressão do seu dinamismo, da sua sucessão, da posição relativa de seus momentos" (Cury, 1985, p.32). Desse modo, as categorias norteiam a interpretação, tanto dos fenômenos mais complexos, que têm maior abrangência e expressam um momento de maior abstração, de articulação com o todo, quanto dos menos complexos, os quais, por sua vez, podem até estar contidos em outros, mas jamais poderão ser vistos como estanques, fixos, não históricos, nem ser apreendidos na sua imediaticidade.

Assim, este artigo limita-se à discussão de algumas categorias, quais sejam, Mediação, Historicidade, Atividade, Subjetividade, Pensamento e Linguagem, Sentidos e Significados. Inicia-se pela categoria Mediação, pois possibilita uma análise não dicotômica da realidade, permitindo a apreensão da relação dialética parte-todo, objetivo-subjetivo, externo-interno, afetivo-cognitivo, sentido-significado. Evita-se, dessa maneira, posições que considerem esses polos como sendo antagônicos ou, ainda, que se tome um ou outro de forma isolada quando, na verdade, são polos complementares de um mesmo processo (Oliveira, 2005). No que tange ao estudo da atividade docente e da subjetividade, a categoria Mediação permite entender que essas dimensões não podem ser entendidas de maneira dissociada. Desse modo, devem ser compreendidas como unidade e, portanto, considera-se que as significações compõem a atividade docente, do mesmo modo que é na atividade que as significações se constituem.

Essa categoria não tem a função de apenas ligar dois polos, mas de ser o centro organizador

264 dessa relação (Aguiar \& Ozella, 2013). Compreender a relação de mediação entre dois elementos implica entender como cada um deles pode:

De um lado, definir a si mesmo, e de outro definir o todo; ser ao mesmo tempo produtor e produto; ser revelador e ao mesmo tempo determinado; ser revelador e ao mesmo tempo decifrar a si mesmo; conquistar o próprio significado autêntico e ao mesmo tempo conferir um sentido a algo mais (Kosik, 1976, p.49).

Na busca pela apreensão do sujeito, a categoria Mediação ajuda na compreensão de que não existem relações diretas, imediatas. Mesmo aquelas que aparentam ser assim, contém, em sua essência, múltiplas determinações as quais, na e pela relação de contradição que mantém, engendram o processo de constituição em que cada fenômeno, "ao realizar-se, cria o outro" (Marx, 1857/1999, p.33). Sendo assim, deve-se buscar entender sua história.

Passa-se, então, à categoria Historicidade, que tem caráter ontológico nessa perspectiva teórica. O "ser social", do qual trata Marx, se constitui humano na sua relação com a natureza e com os outros homens e, nessas relações, constrói sua própria história. "De fato, o homem que luta e trabalha, ao se negar como animal, é um ser essencialmente histórico e é o único a sê-lo: a natureza e o animal não têm história propriamente dita" (Kojéve, 2002).

\section{... . É pela história criada, vivida e relembrada eternamente como tradição que o homem se realiza ou aparece como totalidade dialética, em vez de se aniquilar e desapa- recer por uma negação pura ou abstrata de qualquer dado, seja ele qual for, real e pen- sado (Kojéve, 2002, p.472).}

Deve-se estar atento para que a Historicidade não seja considerada uma simples sucessão cronológica de fatos, um movimento sem rumo, desgovernado (Lukács, 1979). Pelo contrário, trata-se de um movimento determinado por relações de forças dialeticamente articuladas, as quais se constituíram no decurso da existência cotidiana dos acontecimentos, muitas vezes, triviais, comuns, mas constituídos pela totalidade histórica, entendida 
sempre como em movimento, como própria de um período determinado.

O sujeito, na Psicologia Sócio-histórica, é compreendido como aquele que se constitui na relação dialética com o social e a história. Nesse sentido, há necessidade de entender a relação entre a história de cada um, aquela que é diretamente experimentada pelo sujeito individual, e a história social, do mundo. Por isso, na busca por produzir conhecimento sobre a realidade e o sujeito, "'O que é' deixa de ser a pergunta principal para dar lugar à questão de 'como surgiu', 'como se movimentou e se transformou'" (Aguiar \& Ozella, 2013, p.303), permitindo que se apreenda a gênese e o processo de transformação. É importante ter em conta que os instrumentos que mediam a relação dos sujeitos entre si e com o mundo, possibilitando ao indivíduo agir nesse mundo construindo sua própria trajetória também conservam a história daqueles que o precederam.

Nesse sentido, outra categoria importante é a Atividade. Ela está relacionada ao próprio processo de constituição do homem e é nela e através dela que o homem transforma a natureza. À medida que registra essa atividade internamente vai constituindo sua subjetividade. Assim, Atividade e Subjetividade são dimensões categoriais que guardam entre si uma articulação dialética. Para Leontiev (1978), a atividade é uma unidade de vida, molecular - indivisível -, não uma unidade aditiva do sujeito material. É nela e através dela que o homem transforma a natureza para atender suas necessidades e, ao transformá-la, registra internamente essa atividade.

Essa categoria tem, como condição de existência, uma necessidade que, por sua vez, só pode ser satisfeita quando encontra um objeto, ou seja, um motivo que supre uma necessidade específica do sujeito. O motivo pode ser material ou ideal, real ou imaginário. As atividades humanas podem diferir por diversas razões, mas o fundamental, aquilo que distingue uma atividade da outra, é o seu objeto. Nas palavras de Leontiev (1978, p.82): "o objeto da atividade é seu motivo real".
Enfatizando essa proposição, tem-se a contribuição de Newman e Holzman (2002), os quais afirmam que "a qualidade única do trabalho humano, não se encontra na realização de um propósito preconcebido, mas na significatividade... da atividade humana" e que "... . O significado deve ser localizado precisamente na capacidade humana de alterar a totalidade histórica mesmo enquanto somos determinados (em nossa particularidade social) por ela". Essa compreensão também é reforçada por Clot (2006, 2010), que afirma que, ao analisar a atividade de trabalho, é preciso pensá-la não em termos de "atividade realizada", como tradicionalmente vinha sendo feito nas análises ergonômicas, mas como "real da atividade".

A atividade real é, segundo Clot (2006), aquela que se torna aparente, aquilo que de fato é realizado pelo trabalhador. No entanto, o autor chama a atenção para o fato de que a atividade é muito mais do que aquela que é possível de ser observada quando da sua realização, e propõe pensá-la a partir do conceito "real da atividade". Esse conceito envolve aquilo que se fez, mas também aquilo que não se fez, que não se pode fazer, que se tentou fazer sem conseguir, que se teria querido ou podido fazer, que se pensou ou que se sonhou poder fazer, o que se fez para não fazer aquilo que seria preciso fazer ou o que foi feito sem o querer.

Inclui, portanto, a atividade contrariada como constitutiva daquilo que foi realizado, pois ela tenciona a atividade que se torna visível e garante tanto o lugar dos aspectos subjetivos que constituem a atividade quanto sua possibilidade de desenvolvimento. Segundo Soares (2011) "... . O estudo do real da atividade nos possibilita apreender o porquê e o como, isto é, a dimensão subjetiva do conteúdo e da forma de as pessoas agirem diante de situações adversas, desafiadoras" (p.72).

Com a intenção de aprofundar a compreensão da dimensão da subjetividade, recorre-se às categorias Sentido e Significado. Os Sentidos constituem uma articulação particular de eventos psicológicos realizada pelo sujeito em sua relação com o mundo. Como indica Leontiev (1978), "O sentido pessoal representa, não uma consciência 
individual, mas sim minha consciência social" (p.209). O movimento de constituição dos sentidos é complexo, dialético e constante, marcado por zonas mais "instáveis, fluidas e profundas" (Aguiar \& Ozella, 2013, p.304) as quais não é possível apreender em sua totalidade, mas que devem ser mantidas como intenção no processo de análise e interpretação.

Não se pode falar de Sentidos sem incluir seu par dialético, os Significados. Estes correspondem, no campo semântico, às relações que a palavra pode manter com o(s) referente(s) ao reapresentá-lo(s). No campo psicológico é uma generalização, um conceito; produções históricas e sociais por meio das quais os seres humanos se comunicam e socializam experiências (Vygotsky, 2001). Por serem mais estáveis e manterem uma relação dialética com os Sentidos, os Significados são o ponto de partida nas pesquisas do grupo "Atividade docente e subjetividade".

A palavra com significado constitui a unidade de análise. Para entender como isso é possível, é preciso esclarecer, ainda que brevemente, a relação entre pensamento e palavra. Para Vygotsky (2001) "o pensamento não se expressa na palavra, mas nela se realiza" (p.409). Sendo assim, é importante que não se considere o pensamento como sendo expresso em palavras num reflexo especular. Não há uma relação direta entre pensamento e palavra, podendo-se dizer, no entanto, que existe um movimento que vai "do pensamento à palavra e da palavra ao pensamento" (Vygotsky, 2001).

O pensamento se realiza na palavra e, nesse processo, pode-se considerar que muito do pensamento do sujeito fracassa e fica contido no "não dito". O processo que permite ao pensamento se realizar em palavras (ou fracassar) certamente é tensionado e constituído pela subjetividade. Nessa medida, considera-se que, partindo das falas do indivíduo, pode-se, num esforço analítico, empreender um caminho em que mediações e contradições (sempre com o apoio das categorias) são desveladas, de modo que "a face oculta da lua" possa surgir, que os sentidos possam ser apreendidos.

Para finalizar a apresentação das categorias,

266 afirma-se que, para os autores, Subjetividade, como afirma Mitjáns (2005), é uma categoria ontológica, "... . Como forma qualitativa de existência do real irredutível a outros níveis do real, como o biológico e o social" (p.21). Ao referir-se a essa categoria fala-se de um processo específico, em que o social é transformado em psicológico e constitui-se nessa dimensão. Como afirmam Aguiar, Liebesny, Marchesan e Sanchez (2009, p.61) a possibilidade de "... . Complexas reorganizações e arranjos, em que a vivência afetiva e cognitiva do sujeito, totalmente imbricadas na forma de sentidos, é acionada e mobilizada". Acredita-se que assim se pode evidenciar processos os quais permitirão conhecer melhor o docente e suas formas de pensar, sentir e agir na atividade.

Reitera-se, com apoio na categoria Mediação, que subjetividade e objetividade jamais poderão ser entendidas dicotomicamente, e que a dimensão subjetiva inclui a dimensão da objetividade, ainda que não possa ser a ela igualada ou reduzida. Os elementos de subjetividade, os quais se referem ao campo individual, como sentimentos, afetos, emoções, memórias, imagens e pensamentos, têm sua origem no campo social, uma vez que procedem de todas as vivências, inclusive de procedências diferentes, do sujeito. A síntese de todos esses elementos constitui os sentidos do indivíduo.

É a partir do referencial teórico apresentado que procura-se apreender o fenômeno para além da sua aparência e produzir um conhecimento que seja verdadeiramente científico no sentido de revelar o movimento do real, o fenômeno em sua concreticidade (Marx, 1857/1999). Deve-se atentar para que, no processo de pesquisa, a necessária articulação entre o objetivo do estudo, a teoria que o embasa e o método se dê de maneira adequada e coerente. A seguir, serão apresentados os procedimentos utilizados para produção e análise de dados da presente pesquisa, bem como sua articulação com o referencial teórico discutido.

\section{Procedimentos}

Como afirmado acima, as pesquisas realizadas pelo referido grupo têm "a palavra com 
significado" como unidade de análise. Sendo assim, para produção dos dados, optou-se por adotar procedimentos que primassem pelo uso da linguagem e que tivessem o potencial de produzir informações ricas em conteúdo, de modo a permitir a qualidade de análise e interpretação pretendida. Dessa maneira, foram utilizadas entrevistas e sessões de Autoconfrontação Simples (ACS) e Autoconfrontação Cruzada (ACC).

As entrevistas são um procedimento tradicionalmente usado pelo grupo. No momento da realização das mesmas, o pesquisador e o participante colocam-se em um diálogo que não é despretensioso ou desinteressado. Acredita-se, no entanto, que a seriedade e a constante atenção do pesquisador em manter o foco nas informações importantes para alcançar seu objetivo devem estar atreladas a um ambiente amigável, permitindo ao sujeito sentir-se à vontade para falar o mais abertamente possível sobre as temáticas abordadas.

Neste caso, as entrevistas realizadas focaram parte da história de vida - principalmente aspectos referentes à escolarização, escolha profissional e formação docente -, e de forma mais direcionada, a atividade docente. Duarte (2004) aponta, como uma possibilidade das entrevistas, permitir que o pesquisador faça:

Uma espécie de mergulho em profundidade, coletando indícios dos modos como cada um daqueles sujeitos percebe e significa sua realidade e levantando informações consistentes que lhe permitam descrever e compreender a lógica que preside as relações que se estabelecem no interior daquele grupo (p.215).

Os procedimentos de Autoconfrontação Simples e Cruzada são propostas de Clot (2006), as quais coadunam os pressupostos estabelecidos pelo grupo de pesquisa. Assim, ambos têm contribuído com os estudos desenvolvidos nesse âmbito por produzir uma qualidade de dados que favorece maior aproximação com conteúdos os quais permitem apreender os sentidos da atividade docente. Os procedimentos em tela favorecem a ruptura de discursos calcados na reiteração, a reprodução de "discursos vazios" que, muitas vezes, limitam o potencial das pesquisas.
Nas entrevistas, o sujeito é convidado a falar sobre sua atividade a partir das perguntas e intervenções feitas pelo pesquisador. Para a realização das sessões das ACS e ACC, um importante elemento é adicionado: o diálogo se dá a partir da observação que o sujeito faz de si mesmo, em atividade, num episódio previamente gravado e editado pelo pesquisador. Quando descreve sua atividade nas Autoconfrontações, o indivíduo busca fazer com que o outro compreenda o que ele realizou, procurando, para isso, ver sua atividade com os olhos do outro. Nesse momento, encontra alguma coisa de novo em si mesmo.

Para explicar cada um desses procedimentos é suficiente afirmar que a ACS consiste em apresentar os episódios ao sujeito, na presença do pesquisador, e solicitar que descreva, comente, faça questionamentos, ou seja, analise a atividade. $\mathrm{Na}$ ACC, por sua vez, os mesmos episódios são assistidos novamente pelo sujeito da atividade, agora acompanhado também por um especialista ou alguém que conheça em profundidade o cotidiano da profissão.

Além do impacto causado pela imagem, outro aspecto que parece agregar qualidade à informação obtida é a mudança na direção das falas do indivíduo. Como ficou explicitado pela descrição dos procedimentos, durante a realização da entrevista, este fala da sua atividade para o pesquisador sem o impacto de sua própria imagem em ação. Depois, na ACS, é convidado a discursar sobre um aspecto mais específico, vendo-se no vídeo e, por conta disso, elabora justificativas para si num primeiro momento. Em seguida, estas são direcionadas ao pesquisador que questiona sobre aspectos considerados relevantes em relação ao objetivo da pesquisa. Na ACC o participante se dirige a um colega de trabalho. Dessa forma, a direção das justificativas é, então, modificada mais uma vez. Nesse processo de construção e reconstrução de argumentos, aspectos constitutivos da atividade podem ser revisitados, revistos, reelaborados e, portanto, transformados.

Considera-se que, nas Autoconfrontações, na medida em que o sujeito assiste à sua própria imagem e fala sobre ela, cria-se um espaço profícuo 
de desenvolvimento de novos e inusitados recursos, afetivos e cognitivos, possibilitando ao professor refletir sobre sua prática e superar a cotidianidade. O diálogo entabulado pode promover oportunidades para que o sujeito recorra à sua história, à história social e às próprias condições concretas em que está inserido como elementos explicativos, afastando-se do imediato, das explicações costumeiras, cotidianas. Nesse sentido, chama-se a atenção para a importância do pesquisador, que tem a tarefa de conduzir a reflexão para a atividade realizada de modo a ampliá-la.

Para esse movimento reflexivo e crítico acontecer é necessário que o pesquisador tenha a intencionalidade da crítica, que introduza elementos os quais favoreçam esse movimento, de modo a ampliar as possibilidades de desvelamento das mediações constitutivas da atividade do sujeito. Assim, o pesquisador utilizará não somente perguntas sobre aquilo que se tornou aparente (a atividade real), mas recorrerá às contribuições teóricas e metodológicas que, de algum modo, possam trazer novos recursos de reflexão para o indivíduo. Com isso, critica-se a ideia de reflexão esvaziada dos conteúdos historicamente acumulados referentes e constituintes da atividade, no caso, do professor. Aponta-se, ainda, a importância de serem incluídas às reflexões as informações relativas à realidade social, econômica e institucional que conformam a atividade em questão.

A superação de explicações falseadas, naturalizantes e simplistas também é determinada, sem dúvida, pela participação do colega ou especialista da profissão que é convidado para a ACC. No entanto, trata-se aqui especificamente da qualidade da mediação constituída pelo pesquisador porque, como afirmado anteriormente, sua atividade deve ser carregada de uma intencionalidade crítica, não necessariamente compartilhada pelo primeiro.

\section{O compromisso com a transformação da realidade como princípio teórico-metodológico}

De forma coerente à proposição teórico-metodológica aqui apresentada, retoma-se a dis- cussão apresentada sobre a necessidade de produção de um conhecimento que apreenda os movimentos, "as transições... a ligação interna e necessária das partes no todo" (Cury, 1985, p.21). Um conhecimento que tenha o potencial de, ao iluminar a realidade e produzir conhecimento sobre ela, contribuir para sua transformação. Frente a isso, reitera-se que o Materialismo Histórico e Dialético não se contenta em afirmar que as contradições existem, mas que o fundamental é captar a ligação, a unidade, o movimento que engendra os contraditórios. E destaca-se, a partir de Lefebvre (1979), que não existe contradição em geral, mas contradições com conteúdos específicos, concretos e com movimento próprio.

Somente em uma orientação positivista propaga-se a ideia de uma pesquisa pautada no princípio da neutralidade, disposta a revelar uma verdade pura, exigindo, para tanto, que o pesquisador seja neutro e imparcial. No Materialismo Histórico e Dialético, ao contrário, assume-se a contradição como propriedade essencial da realidade.

Ao assumir as noções de historicidade, dialeticidade e materialidade, o grupo de pesquisa aqui discutido não pode sucumbir a concepções que congelam o real, nem crer numa alienação totalizante, fixa, inerte ou insuperável. Avalia-se, assim, ser fundamental a intencionalidade de produzir um tipo de conhecimento que favoreça uma educação denominada emancipadora. Nessa direção, Freire (1996) afirma que "a educação como prática política da liberdade, ao contrário daquela que é prática da dominação, implica a negação do homem abstrato, isolado, solto, desligado do mundo, assim, como também a negação do mundo como uma realidade ausente dos homens" (Freire, 1996, p.70).

Quando se afirma a necessidade de transformação da educação, busca-se indicar a importância de incrementar processos de desalienação e de constituição de práticas as quais permitam ao homem romper com a pseudoconcreticidade e com a desmistificação ideológica de acesso aos conhecimentos socialmente produzidos pela humanidade. Como afirma Mészáros (2004b) "o homem alienado não se apropria de sua essência total como um 
homem total, mas limita sua atenção à esfera do cotidiano, da simples utilidade. Isso provoca extremo empobrecimento dos sentidos humanos" (p.182).

Utilizando as contribuições de Heller (1977), pode-se dizer que ao observar a prática do professor é a cotidianidade que salta aos olhos. Para essa autora, a vida cotidiana é o espaço da alienação, da mesmice, da não reflexão. No entanto, reafirmando o movimento dialético, considera-se que a realidade, da maneira como se apresenta, é formada pela unidade dos contrários, ou seja, por elementos que contém sua própria negação. Compreendê-los para transformá-los implica na necessidade de considerar os fenômenos em sua historicidade, em seu devir.

A alienação contém a desalienação como elemento negado. Do mesmo modo, a não-reflexão contém a reflexão. Assim, o processo de desalienação não é algo inatingível, mágico. Recorre-se a Mészáros (2004b) quando afirma que:

Tal como a alienação não é um ato único (uma queda misteriosa, resultado mecânico) sem seu oposto, a superação da atividade alienada através da atividade autoconsciente, só pode ser concebida como um processo complexo de interação, que produz modificações estruturais em todas as partes da totalidade humana (p.164)

Pode-se, dessa forma, implementar processos junto a educadores que, por meio de um conhecimento científico e crítico, possam questionar, como Mészáros (2004b) indica, "tendências à alienação". A possibilidade de transformação também é apontada por Heller (1977), para quem pode existir, na vida cotidiana, o espaço das "rebeliões sadias" em que o sujeito compreende melhor a si mesmo e ao outro. Reitera-se, assim, que essa ideia de transformação jamais pode ser concebida descolada das condições sociais, políticas e econômicas próprias do momento histórico vivenciado, incluídas aí as condições de classe. Como ensina Pinto (1979, p.208), "cada objeto contém interiormente a ligação dialética com o conjunto de condições que o precedem e das quais procede".
É importante destacar que os processos de transformação citados implicam a construção de espaços democráticos, de colaboração e, principalmente, ancorados na reflexão crítica dos conhecimentos advindos do conjunto da produção humana. Sendo assim, a reflexão pretendida, seguindo o raciocínio de Cury (1985, p.32), deverá alcançar/ apreender as contradições existentes no real, de modo que "... . A natureza dialética do real encontre, na consciência da contradição, sua expressão subjetiva, e também a possibilidade de uma interferência no real". Os autores concordam com Carvalho (2012) quando afirma que "... . A reflexão, quando dialética, tem potencial teórico-metodológico para abrir e expandir zonas de desenvolvimento profissional que gestam possibilidades de transformar o professor em 'ser para si', constituindo-se, assim, instrumento (mediação) e resultado (capacidade psicológica) da formação crítica de professores" (Carvalho, 2012).

As reflexões aqui apresentadas são parciais. A identificação de momentos de transformação da atividade dos sujeitos participantes da pesquisa tem se mostrado difícil: como identificar os momentos de superação? Como saber que aquilo que se observa durante o processo de pesquisa será duradouro? Como saber se aquela mudança que se dá na aparência revela uma mudança na essência do fenômeno? Não existem garantias. Mas, com base no referencial teórico, buscam-se saídas não na neutralidade, nem nas posições dúbias e fugídias, mas em um posicionamento pautado na busca da revelação das determinações e contradições que compõem a atividade docente por meio de um pensamento crítico.

Acredita-se que, dessa forma, pode-se contribuir para uma educação que mantenha, em seu bojo, a articulação dialética entre teoria e prática, que não se esgote na negação unilateral da realidade, que apresente objetivos sustentáveis e seja mediadora dos conhecimentos historicamente acumulados. Essa educação deve, além disso, criticar radicalmente a ordem social e econômica baseada na desigualdade, no cotidiano alienado, arregimentando, desse modo, condições para uma educação transformadora e emancipatória. 


\section{Colaboradores}

O presente artigo foi concebido, planejado e organizado por ambas as autoras, e a leitura final foi feita por W.M.J. AGUIAR.

\section{Referências}

Aguiar, W. M. J. (2001). Consciência e atividade: categorias fundamentais da Psicologia sócio-histórica. In A. M. M. Bock (Org.), Psicologia sócio-histórica: uma perspectiva crítica em Psicologia (pp.95-108). São Paulo: Cortez.

Aguiar, W. M. J., \& Ozella, S. (2013). Apreensão dos sentidos: aprimorando a proposta dos núcleos de significação. Revista Brasileira de Estudos Pedagógicos, 94(236), 299-322. Recuperado em outubro 7, 2014, de http://www.scielo.br/scielo.php?script=sci_arttext \&pid=S2176-66812013000100015\&lng=en\&tlng=pt>

Aguiar, W. M. J., Liebesny, B., Marchesan, E. C., \& Sanchez S. G. (2009). Reflexões sobre sentido e significado. In A. M. B. Bock \& M. G. M. Gonçalves (Orgs.), A dimensão subjetiva da realidade: uma leitura sócio-histórica. São Paulo: Cortez.

Bernardes, A. (2011). Quanto às categorias e aos conceitos. Revista Formação Online, 18(2), 39-62. Recuperado em outubro 7, 2014, de http://revista.fct. unesp.br/index.php/formacao/article/view/602/1225

Bourguignon, J. A. (2006). O processo de pesquisa e suas implicações teórico-metodológicas e sociais. Emancipação, 6(1), 41-52.

Carvalho, M. V. C. (2012). Reflexão crítica e vida cotidiana: mediações para pensarmos a formação crítica de professores. XVI ENDIPE: Encontro Nacional de Didática e Práticas de Ensino, Universidade Estadual de Campinas.

Clot, Y. (2006). A função psicológica do trabalho. Petrópolis: Vozes.

Clot, Y. (2010). Trabalho e poder de agir. Belo Horizonte: Fabrefactum.

Cury, C. R. J. (1985). Educação e contradição: elementos metodológicos para uma teoria crítica do fenômeno educativo. São Paulo: Cortez.

Duarte, R. (2004). Entrevistas em pesquisas qualitativas. Educar, 24, 213-225.

Freire, P. (1996). A educação como prática da liberdade. Rio de Janeiro: Paz e Terra.
Heller, A. (1977). Sociologia de la vida cotidiana. Barcelona: Península.

Kojéve, A. (2002). Introdução à leitura de Hegel. Rio de Janeiro: Contraponto.

Kosik, K. (1976). Dialética do concreto. Rio de Janeiro: Paz e Terra.

Lefebvre, H. (1979). Lógica formal: lógica dialética. Rio de Janeiro: Civilização Brasileira.

Leontiev, A. (1978). Atividade, conciencia y personalidad. Buenos Aires: Ciencias Del Hombre.

Lowy, M. (1987). Aventuras de Karl Marx contra o Barão de Münchhausen: marxismo e positivismo na sociologia do conhecimento. São Paulo: Busca Vida.

Lukács, G. (1979). Os princípios ontológicos fundamentais de Marx. São Paulo: Ciências Humanas.

Marx, K. (1999). Para a crítica da economia política. São Paulo: Nova Cultural. (Originalmente publicado em 1857).

Mészáros, I. (2004a). O poder da ideologia. São Paulo: Boitempo.

Mészáros, I. (2004b). A teoria da alienação em Marx. São Paulo: Boitempo.

Mitjáns, M. A. (2005). A teoria da subjetividade de González Rey: uma expressão do paradigma da complexidade. In F. González Rey. Subjetividade, complexidade e pesquisa em Psicologia (pp.1-26). São Paulo: Cengage Learning.

Newman, F., \& Holzman, L. (2002). Lev Vygotsky: cientista revolucionário. São Paulo: Loyola.

Oliveira, B. (2005). A dialética do singular-particular-universal. In A. A. Abrantes (Org.), Método Histórico-social na Psicologia Social. Petrópolis: Vozes.

Pinto, A. V. (1979). Ciência e existência. Rio de Janeiro: Paz e Terra.

Soares, J. R. (2011). Atividade docente e subjetividade: sentidos e significados constituídos pelo professor acerca da participação dos alunos em atividades de sala de aula (Tese de Doutorado não-publicada). Pontifícia Universidade Católica de São Paulo.

Vygotsky, L. S. (2001). A construção do pensamento e da linguagem. São Paulo: Martins Fontes.

Recebido: março 17, 2014

Versão final: outubro 21, 2014

Aprovado: maio 22, 2015 